\title{
Numerical study of an oil spill containment boom by the finite-element method
}

\author{
F. Muttin \& S. Nouchi \\ Ecole d'Ingénieurs en Génie des Systèmes Industriels, \\ EIGSI La Rochelle, France
}

\begin{abstract}
Oil-spill boom is a technological response to water pollution by floating hydrocarbon. A boom is composed mainly of a floating tube, an immerged skirt, and a longitudinal chain on the skirt bottom. A membrane finite-element is used to represent numerically the different parts of the boom. The dominant external force comes from maritime current velocity. The gravity force comes mainly from the chain. It is balanced by the hydrostatic force applied to the tube bottom line. It is admitted that a sea current higher than $0.35 \mathrm{~m} / \mathrm{s}$ produces oil leaks under the boom. The numerical model is available to study a full boom contingency planning. A boom section model is defined first, having a minimal number of degrees of freedom. It permits using a homothetic scaling to provide an accurate length model. After, by applying a duplication operator, a real-life length model is obtained $(\mathrm{L}>750 \mathrm{~m})$. It is completed by the mooring of the barrage on the sea bed. The different assumptions made on the elementary model are given. Operational results on a boom contingency planning are also given. Parameters like skirt angle, skirt curvature, and chain stress, handle the boom response performances. This work was undertaken with the support of the French Environmental Administration.
\end{abstract}

Keywords: hydrocarbon, oil-spill boom, contingency planning, finite-element.

\section{Introduction}

To recover oil on water during an oil-spill different mechanical responses are commonly used: confinement boom, skimmer pump and "koseq" rigid dikes on both sides of the recovery vessel. This paper presents the study of booms by a numerical analysis. 
Some software is used for boom computations. Generally they are based on analytic formulas. The shape of boom sections is approach by the catenary curve $\cosh (\mathrm{x})$. It may depend on boom section length, and the boom section cord length. The mathematical expression of such curve can be $a \cosh \left(\frac{x-b}{a}\right)+c$ where $\mathrm{a}, \mathrm{b}$ and $\mathrm{c}$ are shape parameters computed numerically using boundary conditions [1].

Reference [2] is the first boom analysis by finite-element. It uses "beam" and "plate" elements. It is the only know reference for boom structural analysis by finite-elements. In that study the elements are both bending stiffness element and membrane stiffness element. Our study will use cable and membrane elements, which are the best suited for flexible structure analysis. Note that boom displacement can be large under tide and current effects.

The next reference [3] concerns a feedback study of the boom usage on the Atlantic coastal zone in 1993. It indicated the non-validity of a majority of boom contingency plannings in 1993 concerning high tides and high currents coastal zones.

Reference [5] uses the "Volume of fluid" VOF method, to provide the optimal positions of juxtaposed and parallel booms plans. The flow is assumed to be $2 \mathrm{D}$ in the vertical plane. The multiplicity of the booms permits the oil droplets which have gone under the first boom to be catch by the $2^{\text {nd }}$ and third booms.

In reference [6], the boom cross-section is approximated by a vertical beam. Two main hypotheses are study concerning a priori boundary conditions on both sides of the beam: free - embedded or simple support - simple support. These boundaries conditions reflect hypothesis on the structural response of the boom longitudinal parts: a chain and a floating pressurized tube. A fluid-structure computation is proposed using 2D fluid flow around the beam.

Reference [7] proposes to study two a priori choices to provide the mathematical functions for the boom equilibrium shape: catenary function (cosh $\mathrm{x})$ or parabola $\left(\mathrm{x}^{2}\right)$.

The software FORBAR solves a non-linear equation to define both the tension vector $\mathrm{T}$ of the boom and the shape curve of the boom. The solution of the non-linear equation is obtained iteratively [8].

The problem tackled in this paper, is to construct a scientifically based method to compute the boom behaviour under the sea current effect. The sea current is the most important source of external force, compared to waves and wind actions. External force action is linked to the oil leakage observed around boom. The boom behaviour given by our model concerns the boom shape in 3D and its membrane stress. For that purpose, we used the finite-element method, based on a quadrilateral membrane element.

\section{Boom theory}

The simplest model to obtain the boom tension $\mathrm{T}(\mathrm{x})$ in terms of the applied force $\mathrm{f}$ is the first order ODE $T^{\prime}(x)=f(x)$. It can be solve by a simple integration of 
the applied force $\mathrm{f}(\mathrm{x})$, taking into account an a priori hypothesis on the boom stress on a boundary condition $\mathrm{T}_{0}$.

We obtain: $\mathrm{T}(\mathrm{x})=\mathrm{T}_{0}+\int_{0}^{x} f(x) d x$. The tension $\mathrm{T}$ and the boom shape can be adjusted by tests on the value given to $\mathrm{T}_{0}$ (direction and magnitude). Nevertheless, this simple model does not take into account the boom deformation and the 3D geometrical aspects.

New boom conceptions must be also analyzed, such as Straight boom [9]. This boom is adapted to river and estuary, with high current. Its shape is straight. It permits to reduce the oil leakage. The straight shape is obtained by giving a high longitudinal tension $\mathrm{T}$ in the boom, with both following concepts. First, an angle $\alpha$ is given between the boom orientation and the current velocity vector. Secondly, a mooring system is placed on both sides of the boom, with the sufficient density of anchoring points. The angle $\alpha$ permits to reduce the boom tension $\mathrm{T}$. The drawback of this barrage kind is the difficulty to conserve a straight shape with a variation of the sea depth, under the tide effect. A variation of the water height gives a variation on the boom shape, under the assumptions of a fixed length mooring system, and a non-uniform bathymetry. On the other hand, the boom will resist to the current effect in the upstream or downstream directions only when the mooring system is on the both sides of the boom.

A numerical value often mentioned to fit the boom shape is the tension of its chain. This tension can be adapted by a turnbuckle. Our theoretical model can take the chain pre-stress by reducing by a scalar the initial length of the chain finite-elements.

Other innovations on boom have been proposed: Sinusoidal boom [10], Cascade boom [11] or Encircling boom [12].

A boom contingency plan is composed of several parts: the floating components, and the anchorage system. The floating system is composed of a buoyancy inflated tube, an immerged skirt, a weighted chain on the skirt bottom and a stressed leech on the skirt top.

The floating system is moored to buoyancy coffers. These coffers are anchorage on the sea bed with anchors and mooring lines. Generally the mooring line length is 3 times the sea depth.

Note that at the two ends of contingency plan, we can have two opposite difficulties: deep sea or no water. If the sea depth is high the coffer moves on a large area during the tide. When the sea depth is null the boom is grounding and it can not be stressed longitudinally without damage on its structure.

The boom behaviour to confine the oil can be seen over a vertical and transversal section of a boom. It consists to imagine a vertical inverted pendulum (barrage) with a buoyancy device fixed at the immerged chain. Under sea current action the pendulum (barrage) moves around the chain as showed on fig. 1 . Consequently the skirt can have an angle $\theta$ with the vertical crossing the chain. The skirt angle changes the flow regime around the boom section. Depending of this regime, of the current velocity, and of the oil density, a leakage of the confined oil can be observed. When the current velocity is higher than $0.35 \mathrm{~ms}^{-1}$, it is observed oil leakage with boom system. 


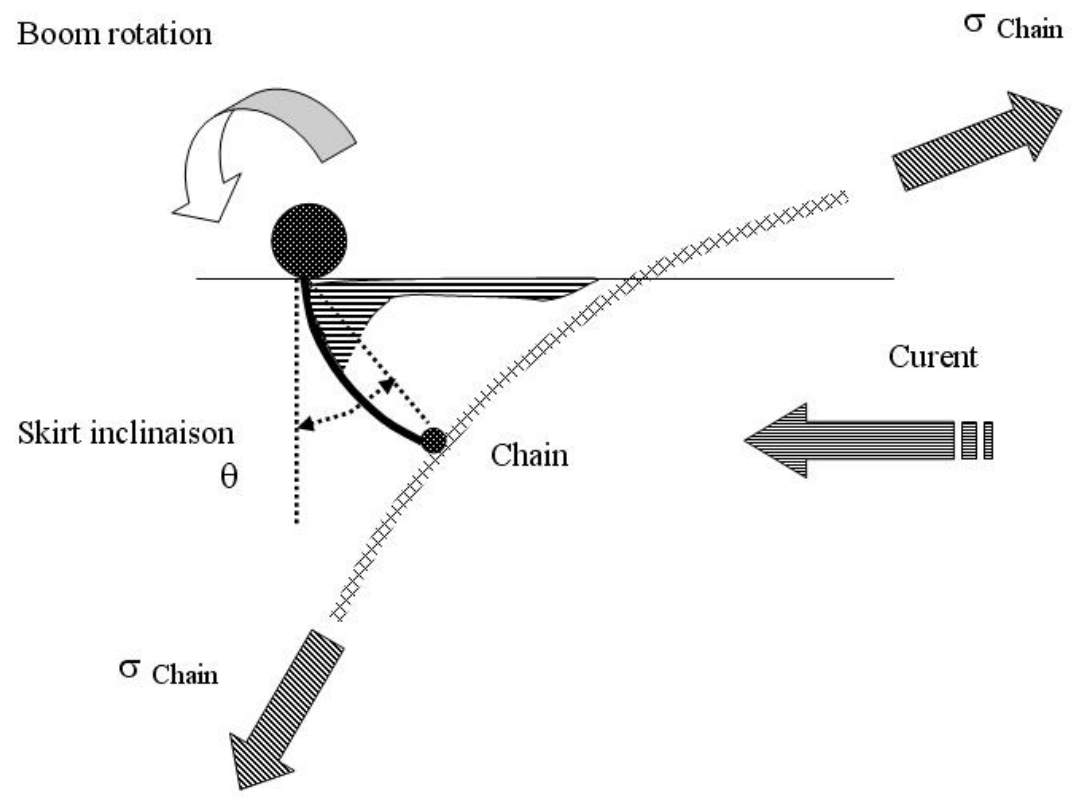

Figure 1: $\quad$ Boom inclination by torsion around its stressed chain.

When the current velocity is higher than $0.35 \mathrm{~ms}^{-1}$, the boom system is used to deviate the oil and not to confine it. In the deviation case, the angle $\alpha$ between the current velocity and the boom direction is chosen so that the boom remains straight (vertical) with limited longitudinal stress. Nowadays, we need innovations on the anchorage system, including mooring lines topology, in order to limit the stress in the boom.

The torsion effect of a boom section around the immerged longitudinal chain, more the boom sinking under the current effect, are the most observed effects in the computational results on the boom shapes. While the stress in the chain and in the leech are the most observed computational results on the boom stress.

On fig. 2, it can be seen different components of a boom contingency plan. Remark: The integration of the ODE $T^{\prime}=f$, permits the control of the boom tension at only one of its extremities. To control the solution at both boom extremities, we can introduce the deformation $\varepsilon(\mathrm{x})$ in term of a location $\mathrm{x}$ on the boom. We define the boom tension by $\mathrm{T}(\varepsilon(\mathrm{x}))$. Consequently the equation becomes $T^{\prime}(\varepsilon(x))=f(x)$. This equation can be solved with respect to fixed displacements as boundary conditions on both extremities of the boom. Another way, for the same objective, consists to define a minimization problem, based on the energy deformation of the boom, minus the potential energy of the applied loads. The boom deformation energy is defined by $\int 1 / 2 k \varepsilon^{2}(x)$, where $\mathrm{k}$ is the 
elasticity constant of the boom. The membrane finite-element formulation used in this study is a generalization of this last approach.

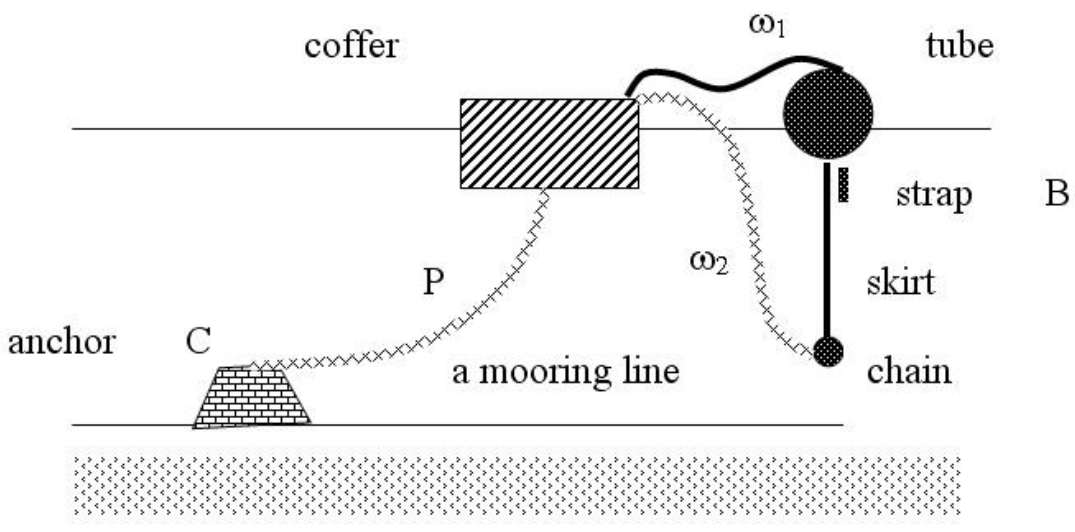

Figure 2: Boom anchorage system.

\section{Finite-element model}

Let $\mathrm{B}$ be the domain of a boom device and $\omega$ be the B-ended bale rong (or bridle) system attached to a buoyancy coffer. We define a boom section $\mathrm{X}$ by the following sets union eqn (1), where the label $\pm 1 / 2$ denotes the right and left sides of X.

$$
X=B \cup \varpi_{ \pm 1 / 2}
$$

A general boom section is constructed with eqn (2), by the means of a scaling ratio $\lambda$, and the union of a mini skirt $m$ on the right side of the device $(+1 / 2)$. It permits to link two sections, and to guarantee the impermeability of the boom contingency plan between two adjacent sections.

$$
X_{G}=\lambda X \cup m_{+1 / 2}
$$

A general boom contingency plan is defined in eqn (3), by the union of Nbtron sections, translated by a multiple of the section length $\mathrm{L}$. The term $\mathrm{a}_{ \pm 1 / 2}$ denotes the mooring system between $\omega$ and the sea-bed. The last mini skirt $\mathrm{m}_{\mathrm{Nbtron}}$ must be avoided in the last boom section.

$$
X_{M}=\bigcup_{i=1}^{N b t r o n}\left(X_{G}+(i-1) L+a_{ \pm 1 / 2}\right)-m_{\text {Nbtron }+1 / 2}
$$


On each mooring system $\mathrm{a}_{\mathrm{i}}$, we define two points: the sea bed point $\mathrm{C}_{\mathrm{i}}$, and the mooring line middle point $\mathrm{P}_{\mathrm{i}}$,

$$
(P, C)_{i^{\prime}} \in a_{i^{\prime}} ; \quad i^{\prime}=i \pm 1 / 2
$$

At time $\mathrm{t}=0$, corresponding, for example, to the high tide sea level, we define by eqn (5) the location of the mooring line middle point $\mathrm{P}_{\mathrm{i}^{\prime}, 0}$, by using the given length of the mooring line $\mathrm{L}_{\mathrm{i}}$, . The sea bed point $\mathrm{C}_{\mathrm{i}, 0}$, is fixed by the bathymetric co-ordinates of the anchor on the sea bed.

$$
\left\|a_{i^{\prime}, 0}\right\|=L_{i^{\prime}} \quad \rightarrow P_{i^{\prime}, 0}
$$

Under the sea level variations, with the tide effect, at each time $t$ of a representative day, we define a vertical displacement of the sea bed points. The boom location remains fixed. The vertical variation of the water height is denoted $\delta h_{t}$ in eqn (6). The position of the mooring line middle points $\mathrm{P}_{\mathrm{i}, \mathrm{t}}$ is defined so that the mooring line lengths remains constant.

$$
\left\{\begin{array}{c}
C_{i^{\prime}, t}=C_{i^{\prime}, 0}+\delta h_{t} \\
P_{i^{\prime}, t}=P_{i^{\prime}, 0}+\delta p_{t} ; \quad\left\|a_{i^{\prime}, t}\right\|=L_{i^{\prime}}
\end{array}\right\}_{i=1, \text { Nbtron } ; t=0,2,4,6,8,10 h}
$$

The deformed state of the boom contingency plan $\widetilde{X}_{M, t}$ at any time $\mathrm{t}$ can then be computed [13-15].

As a post-treatment we define two main values, over all boom sections $i$, and over all time $\mathrm{t}$ : the maximum of the skirt angle in the middle of a boom section, the maximum chain stress in the middle of a boom section. It are defined by the eqn (7)

$$
\widetilde{X}_{M, t} \rightarrow\left\{\begin{array}{c}
\overline{\bar{\theta}}=\operatorname{Max} \theta_{i, t} \\
\overline{\bar{\sigma}}=\operatorname{Max}_{c h} \sigma_{i, t}
\end{array}\right\}_{i=1, \text { Nbtron } ; t=0,2,4,6,8,10 \mathrm{~h}}
$$

\section{Numerical results}

Here follows the computation of a single boom part B, having $150 \mathrm{~m}$ long. We consider two current velocities: 0.3 and $0.7 \mathrm{~ms}^{-1}$. These velocities border the critical velocity of $0.35 \mathrm{~ms}^{-1}$, where oil leakage is observed in real conditions. The boom section shape has initially a normal direction with the current $(\alpha=0)$. We will see on fig. 3 that the boom shape has longitudinal variation 
corresponding to stress increase. On the central transversal section of the boom, we see on the same figure that the skirt angle $\theta$ changes, as its curvature, too. The evolution of both shape and stress parameters are given in table 1 .

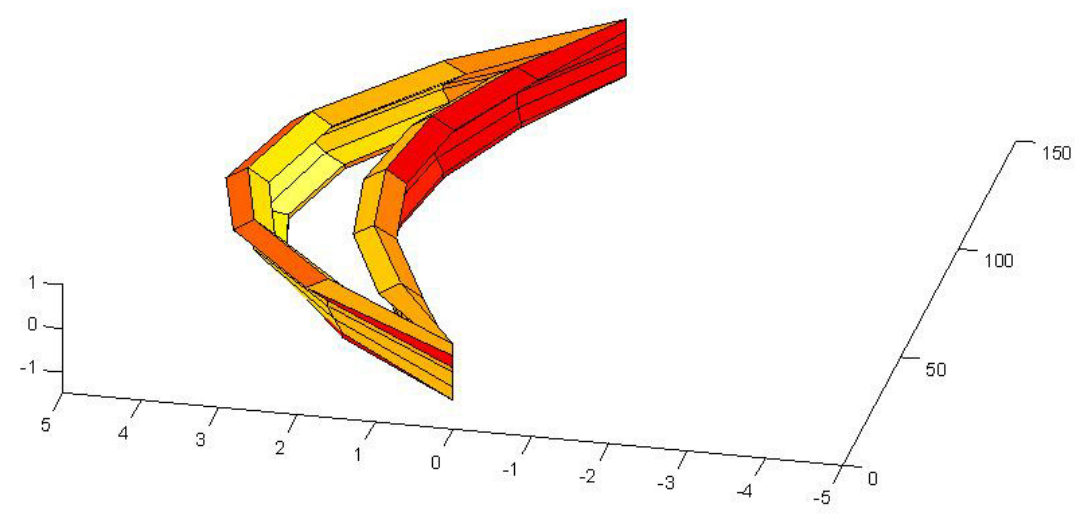

Figure 3: Influence on the boom shape of the marine current velocity $(0.3$ and $0.7 \mathrm{~ms}^{-1}$ )

When the current velocity increases, we notice that the top of the skirt moves with the current, and that the floating tube has the tendency to sink.

The augmentation of the current velocity has the strong effect to modify the skirt angle $\theta$ from $-13^{\circ}$ to $-49^{\circ}$. It is observed a strong modification of the skirt radius of curvature, too.

Table 1: Variations of shape parameters and stresses in term of maritime current velocity $\left(0.3\right.$ and $\left.0.7 \mathrm{~ms}^{-1}\right)$.

\begin{tabular}{|c|c|c|}
\hline Current velocity $\left(\mathrm{ms}^{-1}\right)$ & 0,3 & 0,7 \\
\hline Skirt angle $\theta$, middle skirt $\left(^{\circ}\right)$ & $-13,1$ & $-49,2$ \\
\hline Horizontal disp., skirt top $(\mathrm{m})$ & 1,97 & 3,74 \\
\hline Vertical disp., skirt top $(\mathrm{cm})$ & $-4,75$ & $-31,8$ \\
\hline Chain stress $\sigma_{\mathrm{ch}}$, boom middle $\left(\mathrm{Nm}^{-1}\right)$ & $8,17 \mathrm{e}+5$ & $26,6 \mathrm{e}+5$ \\
\hline Leech stress, boom middle $\left(\mathrm{Nm}^{-1}\right)$ & 864 & 2900 \\
\hline Curvature, skirt middle & 0,513 & 0,773 \\
\hline Radius of curvature, skirt middle $(\mathrm{m})$ & 1,95 & 1,294 \\
\hline
\end{tabular}

Here follows the resulting shape of a boom contingency plan $\mathrm{X}_{\mathrm{M}}$ composed of Nbtron $=5$ boom sections. The deformed shape $\widetilde{X}_{M, 0}$ under a normal current of $0.3 \mathrm{~ms}^{-1}$ is showed on fig. 2 . The current action is the solely maritime external force. Wind action and wave action are neglected. As boundary condition on the right and left sides of $\mathrm{X}_{\mathrm{M}}$, we impose that the nodes of the two extreme B-ended bale rong systems $\omega_{1-1 / 2}, \omega_{\mathrm{Nbtron}+1 / 2}$ remain in the vertical plane. 


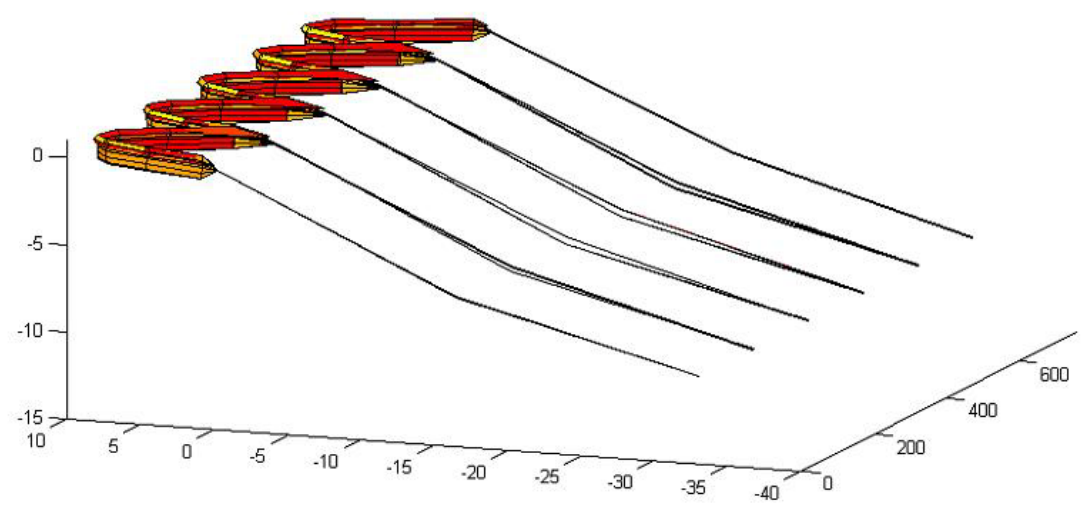

Figure 4: Boom contingency plan computation.

The mooring lines have self weigh loading. On fig. 3 we can see some mooring line middle points $\mathrm{P}$ and the sea bed points $\mathrm{C}$, where the anchors are placed.

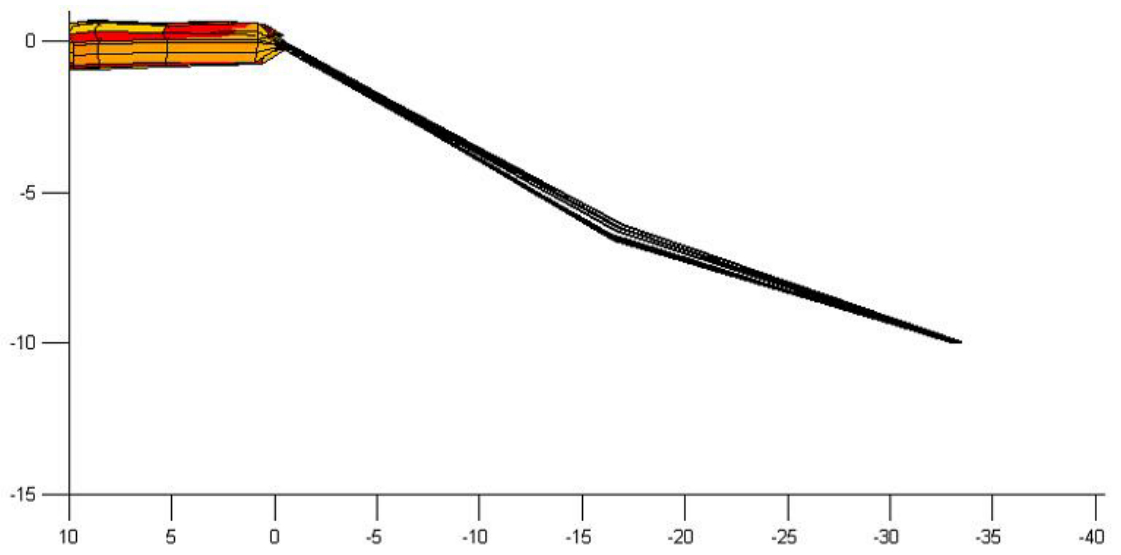

Figure 5: Boom contingency plan computation

On the top extremities of the mooring lines, Nbtron buoyancy coffers are positioned. The buoyancy of a coffer motion is simulated by cancelling the vertical displacement of the finite-element nodes placed between the B-ended bale rong systems $\omega_{\mathrm{i} \pm 1 / 2}$. and the mooring system $\mathrm{a}_{\mathrm{i} \pm 1 / 2}$. The reaction force along this degree of freedom indicates the buoyancy forces required. More precisely, if this reaction force exceeds the buoyancy limit of the coffer, it indicates that this coffer buoyancy is insufficient.

The reaction force on a sea bed point $\mathrm{C}$ gives the traction force resulting on the anchor. Depending of the nature of the sea floor (sand, rocks, or mud) this 
force magnitude permits to validate the means used on the sea bed to attach the bottom extremity of the mooring system $\mathrm{a}_{\mathrm{i} \pm 1 / 2}$ (anchor or dead-mass).

\section{Conclusion}

The next step of our research will be the computation of the boom contingency plan on the river "Elorn" in the sheltered road of Brest (France). The finiteelement mesh will be over Nbtron $=6$ boom sections. The bathymetry of the river is non constant, while, the water height can vanished during tide on both sides of the boom contingency plan.

To improve our structural computations, we will compare our results with experimental results. At this stage, we must mention the two following points. First the comparison of the boom shape between experiment and computations can be done easily along the longitudinal orientation by comparing the boom shape with aerial views. Nevertheless the comparison of the boom shape in the transversal orientation appears must complex to achieve. The second point concerns the boom comparison performance on the oil containment, which is the main issue. On that point it appears that the comparison of computational result with experiment must use hydrodynamic computation of the oil motion. We mention here that the hydrodynamic analysis is generally performed in twodimension, with straight boom cross-section. The cross-sections are generally supposed vertical. The main result provided by structural computation reveals that a boom cross-section has a curvature and an angle with the sea surface.

A next step can be reach with fluid/structure interaction computation in threedimension.

\section{Acknowledgements}

This research is supported by the French Ministry, Ministère de l'Ecologie et du Développement Durable, MEDD, under grant $\mathrm{n}^{\circ} \mathrm{CV} 13$ 2003, Accord $\mathrm{n}^{\circ} \mathrm{CV}$ 03000142. The authors acknowledge the French framework, Réseau de Recherche et d'Innovation Technologique (RRIT), Ritmer: "Pollutions Marines Accidentelles et leurs Conséquences Ecologiques".

\section{References}

[1] Delgado, L., Kumzerova, E., Martynov, M., Mirny, K. \& Shepelev, P., Dynamic simulation of marine oil spills and response operations, 4th International conference on hydrocarbon spills, modelling, analysis and control, OIL-SPILL 2004, Alicante, Wessex Institute of Technology, Universidad de Alicante, 28-30 April 2004.

[2] Badesha, S. S., Hunt, J. \& Wenck, E., Structural Analysis of Oil Containment Booms, Proc. International Oil Spill Conference IOSC 2005, Index by year \& title pp. 199, International Oil spill conference 1993. 
[3] Fauvre, D., Evaluation and limits of protecting boom plans for high tidal range and strong current areas, Proc. International Oil Spill Conference IOSC 2005, Index by year \& title pp. 214, International Oil spill conference 1995 .

[4] Fang, F. \& Johnston, A.J., Oil Containment by Boom in Waves and Wind. I: Numerical Model, J. Wtrwy., Port, Coast., and Oc. Engrg., 127(4), pp. 222-227, 2001.

[5] Fang, J. \& Wong, K.-F. V., Optimization of an oil boom arrangement, Proc. International Oil Spill Conference IOSC 2005, Index by year \& title pp. 340, International Oil spill conference 2001.

[6] Amini, A., Mahzari, M., Bollaert, E. \& Schleiss, A., Fluid-structure interaction analysis applied to oil containment booms, Proc. International Oil Spill Conference IOSC 2005, Index by year \& title pp. 405, International Oil spill conference 2005.

[7] Lasserre, J., Etude dynamique du comportement des barrières flottantes, Proc. colloque ASTEO, Kléber-Colombes Industry, February 1974

[8] Darras, M., Mise en auvre des barrages antihydrocarbures, exemple d'application du programme Forbar: l'estuaire de l'Orne, Industrial report, Laboratoire National d'Hydraulique, EDF $\mathrm{n}^{\circ} \mathrm{HE} / 42.84 .26$, September 1984

[9] MJ Information, 'V' booms victorious Pollution Trial, Maritime Journal, pp. 41, November 2005

[10] Wong, K.-F. V., Stewart, H. O., Oil Spill Boom Design for Waves, Spill Science \& Technology Bulletin, 8(5-6), pp. 543-548, 2003

[11] Wong, K.-F. V., Barin, E., Oil Spill Containment by a Flexible Boom System, Spill Science \& Technology Bulletin, 8(5-6), pp. 509-520, 2003

[12] Sayah, S. M., Boillat, J.-L. \& Schleiss, A., Behavior of a Contractile Floating Reservoir for the Confinement and Recovery of Oil Slicks, J. Wtrwy., Port, Coast., and Oc. Engrg., 130(5), pp. 266-271, 2004.

[13] Muttin, F., Guyot, F, Nouchi, S. \& Variot, B., Experimental Numerical and Optimisation Study of Oil Spill Containment Boom, Proc. Coastal Environment V incorporating Oil Spill Studies, 4th International Seminar on Hydrocarbon Spills Modelling, eds. C.A. Brebbia, J.M. Saval Perez, L. Garcia Andion \& Y. Villacampa, WIT Press, Universidad de Alicante, Wessex Institute of Technology, pp. 421-430, 2004.

[14] Boushaba, F., Nouchi, S., Benelmostafa, Y. \& Muttin, F., Structural Modelling of Oil Spill Containment Booms by the Finite Element Method, Proc. international Oil Spill Conference IOSC 2005, Index by year \& title pp. 424, International Oil spill conference 2005.

[15] SIMBAR, simbar.eigsi.fr 